\title{
Antes da Corte: população e pobreza no Rio de Janeiro, c.1763-c.1808
}

\author{
Before the Royal Court: population and poverty in Rio de \\ Janeiro, c.1763-c.1808
}

\author{
Renato Pinto Venancio 1
}

RESUMO

Antes mesmo da chegada da família real, em 1808, o Rio de Janeiro havia se transformado no principal centro urbano da América portuguesa. No entanto, isso tinha implicações negativas para a população mais pobres. O aumento demográfico fazia com que os preços dos alimentos básicos subissem, assim como tornava mais difícil o acesso a terrenos para construção de habitações. O presente artigo analisa o impacto dessa situação no aumento de óbitos de pobres registrados na Santa Casa da Misericórdia carioca.

Palavras-chave: Escravidão; Rio de Janeiro; 1808; Pobreza.

\section{ABSTRACT}

Even before the arrival of the royal family in 1808, the city of Rio de Janeiro had turned into the major urban center of the Portuguese America. Nevertheless, this fact had negative implications for the poorest people. Demographic growth caused a raise in basic food prices, and also made accessibility to land for residential construction more difficult. This article analyses the impact of such a situation on the increase of poor people's death records of Rio hospital Santa Casa de Misericórdia.

Keyword: Slavery; Rio de Janeiro; 1808; Poverty.

Em meados do século XVI, após a expulsão dos invasores franceses, ocorreu a ocupação efetiva do Rio de Janeiro. De maneira geral, pesquisas eruditas sugerem que o sítio urbano

1 Doutor em História Social, professor na Escola de Ciência da Informação da Universidade Federal de Minas GeraisUFMG e Pesquisador do CNPq. Em 2012, publicou o livro Cativos do Reino: a circulação de escravos entre Portugal e Brasil, séculos 18 e 19. São Paulo: Alameda, 2012. E-mail: rvenancio@eci.ufmg.br 
originou-se das sesmarias concedidas à Mem de Sá, em 1567, abrangendo légua e meia em quadrado;(SANTOS, 1965, p. 24) pouco mais de seis quilômetros quadrados, fazendo fronteira com areais e alagadiços situados em uma das reentrâncias da baía de Guanabara. As primeiras casas construídas nos arredores do Pão de Açúcar começaram, então, a ser transferidas para os aterros primitivos, localizados entre os morros do Castelo e o de Nossa Senhora da Glória.

A escolha da área não se deu ao sabor do acaso, em grande parte ela decorria da astuta percepção militar das autoridades metropolitanas. Ao transferir o núcleo colonial para as praias do interior da baía, os portugueses passaram a contar com ponto geográficos para a edificação de fortificações que garantiam a defesa contra incursões de piratas e invasores (BERNARDES, 1960, p. 92).

Contudo, as vantagens militares advindas da localização do núcleo carioca traziam consigo grandes inconvenientes do ponto de vista urbanístico. Ao ser transferida para o interior da baía, a cidade do Rio de Janeiro deixou de possuir espaço para se expandir. A lagoa do Boqueirão, os alagadiços e pântanos de São Diogo e da Gamboa Grande, aterrados somente em fins do século XVIII (LISBOA, 1840, v. 1, p. 13-14), em larga medida impediram o avanço da construção de moradias rumo ao interior. Por outro lado, as escarpas da Serra da Carioca, os morros de Santa Tereza, de Santo Antonio, da Sentinela, do Catumbi e da Glória restringiram a ocupação litorânea a uma pequeníssima faixa em direção ao oeste e ao sul.

A futura capital colonial surgiu cercada pelo mar, lagoas, areais, pântanos e montanhas. Tal situação marcou profundamente a história do Rio de Janeiro. O núcleo carioca, em virtude de possuir um sítio urbano mínimo, nasceu, por assim dizer, "densamente povoado", principalmente quando comparado a outra localidades coloniais ${ }^{2}$. Porém, não é tarefa fácil conhecer o número desses habitantes. A documentação, além de escassa, apresenta divergências entre uma fonte e outra. Infelizmente, os cariocas não dispõem - ou pelo menos até agora não foram identificadas - de listas nominativas, tais quais as localizadas para São Paulo e Minas Gerais. Os registros eclesiásticos de batismos, casamentos e óbitos apresentavam enormes lacunas, tendo sido conservado de forma seriada somente para a segunda metade do século XVIII; por outro lado, os livros de desobriga (ou seja, aqueles que registravam a população em idade de confessar e comungar) informam apenas os indivíduos maiores de sete anos.

Antes de compararmos os dados das diversas localidades indicadas na tabela, cabe salientar que nela não aceitamos as estimativas produzidas por viajantes. No caso específico do Rio de Janeiro, tais testemunhos são afetados por especificidades locais. Conforme se mencionou, ao contrário de outros núcleos coloniais, a capital carioca constituiu-se em território bastante restrito: espremido entre praias, montanhas e pântanos, o espaço urbano

${ }^{2}$ A cidade de Salvador, por exemplo, possuía $36 \mathrm{Km}^{2}$. (MATTOSO, 1992. p. 100). 
local cobria uma faixa restrita do território. Influenciados pela forte densidade populacional, muitos viajantes fizeram estimativas elevadas, e até mesmo exorbitantes, do número de habitantes. Assim, Nicoles Louis de la Caille, francês que visitou o Rio em 1751, avaliou em $50 \mathrm{mil}$ a população local; cifra que equivalia a aproximadamente o dobro do que constava da documentação administrativa. Outra estimativa exagerada foi aquela avançada por John Barrow que, em 1792, estimou a população local em 60 mil almas; número atingido somente duas décadas mais tarde. Mais surpreendente ainda foi o caso de James Nelson que, em 1796, permaneceu uma semana no Rio, e, muito impressionado com a intensa movimentação das ruas cariocas, registrou uma estimativa espetacular: a capital colonial contaria com 200 mil habitantes; cifra, cabe lembrar, cinco vezes mais elevada do que a oficial (FRANÇA, 1999, p. 98-217).

Tabela 1 - População das principais vilas e cidades da América portuguesa, 1760-1808

\begin{tabular}{|c|c|c|c|c|c|c|c|}
\hline Cidade & 1760 & 1779 & 1789 & 1796 & 1799 & 1804 & 1808 \\
\hline Rio de Janeiro & 32.746 & & 36.932 & & 43.376 & & 50.144 \\
\hline Salvador & 39.466 & & 40.398 & & 40.912 & & 43.147 \\
\hline Ouro Preto* & & & & c.20.000 & & 8.867 & \\
\hline São Paulo & c.20.000 & & & & 21.304 & 24.311 & \\
\hline Recife & & c. 15.000 & & & & & c. 25.000 \\
\hline Belém & & c.9.000 & & & & & c.11.000 \\
\hline Curitiba & c.7.000 & & & & 6.478 & 7.804 & \\
\hline Porto Alegre & & c. 2.000 & & & & & c. 6.000 \\
\hline
\end{tabular}

Fontes: Johnson (1973, p. 44); Nascimento (1986, p. 65); Morse (1971, p. 23-111); Costa (1979, p. 243); Costa (1985, p. 27, 53); Marcilio (1973, p. 127); Notícias de todos os governos e população do Brasil (1782). Biblioteca do Palácio da Ajuda, Lisboa, cód. 54-V-12, n. 5.

Frente ao testemunho de viajantes, as fontes administrativas são bem mais confiáveis e a razão disso é de fácil compreensão. Os vice-reis e oficiais da câmara necessitavam conhecer em detalhes o número de habitantes e de domicílios, pois dessa informação dependia a cobrança de impostos e o recrutamento militar. A tabela I, dessa maneira, considera apenas os dados que foram colhidos em documentos oficiais. Nela, como pode ser percebido, a população de Salvador é registrada com grande precisão numérica. O mesmo, 
porém, não pode ser afirmado em relação a outras localidades. Em Ouro Preto, por exemplo, a estimativa populacional de 1796 foi produzida por fonte administrativa portuguesa e conservada no Palácio da Ajuda de Lisboa. Apesar da origem oficial, ela é bastante vaga, não indicando as paróquias incluídas na contagem; problema semelhante é percebido no levantamento populacional de outros centros coloniais. $O$ que, no entanto, não impede de aceitá-las, principalmente quando complementadas por avaliações precisas, avançadas por Maria Luíza Marcílio, Iraci del Nero da Costa e Horácio Gutiérrez.

Se aceitarmos esse conjunto de estimativas, perceberemos que Salvador, até por volta de 1789, era o principal núcleo urbano do Brasil colonial. Ao longo da década seguinte, o Rio de Janeiro ultrapassa a antiga capital, talvez refletindo um processo de recuperação econômica que vinha sendo registrado desde a década anterior. Portanto, dez anos antes da chegada da família real, o Rio de Janeiro havia se tornado a cidade mais populosa da América portuguesa. Em 1808, os cariocas ampliaram a diferença frente aos soteropolitanos e se tornaram duas vezes mais numerosos do que os recifenses e oito vezes mais do que os portoalegrenses.

Em fins do século XVIII, mesmo de acordo com os padrões europeus, o Rio de Janeiro podia ser considerado uma "grande cidade". Na tabela II, apresentamos o resultado da comparação entre a evolução populacional carioca e a registrada nos principais centros urbanos portugueses - ou seja, aqueles que na época possuíam mais de dez mil habitantes. Conforme pode ser percebido, Lisboa era, sem sombra de dúvida, a maior cidade do Império português e uma das maiores da Europa. Nem mesmo o devastador terremoto de 1755 conseguiu abalar essa primazia, comprometendo apenas os índices de crescimento local. Em Évora, por outro lado, o terremoto levou a uma drástica diminuição da população local. Quando comparada aos demais grandes centros urbanos metropolitanos, a capital carioca vinha em segundo lugar, apresentando um perfil muito semelhante ao da cidade do Porto, tanto em números absolutos quanto em índices anuais de crescimento populacional. No Novo Mundo, o Rio também ocupava papel de destaque, sendo, na América Latina, um núcleo populacional urbano superado apenas pela cidade do México, Puebla, Lima e Havana $^{4}$; e, mais ao norte, por Filadélfia e Nova Iorque. ${ }^{5}$

Tendo em vista o padrão demográfico da época, a ocorrência de um rápido crescimento populacional urbano deve ser visto como algo excepcional. Quanto a isso, basta mencionar que, no início do século XVI, uma "grande cidade" europeia seria toda aquela que contasse, no mínimo, entre 15 e 20 mil habitantes; ao passo que, no início do século XIX, essa cifra

${ }^{3}$ Cifra também reproduzida em "mapas de população, Ouro Preto, 1796-1797, Arquivo Público Mineiro, planilhas 2037". (RAMOS, 1979, p. 496). Em relação à evolução urbana de Ouro Preto (antiga Vila Rica). (FONSECA; VENANCIO, 2008. p. 179204).

${ }^{4}$ Em 1793, a cidade do México possuía aproximadamente 113 mil habitantes; Puebla , 57.090; Lima, 53.000; e Havana, 51 mil. (MORSE, 1971).

${ }^{5}$ Em 1800, Filadélfia possuía 62 mil habitantes, enquanto New York contava com cerca de 61 mil habitantes. (NASH, 1987, p. 115). 
oscilaria entre 50 e 70 mil indivíduos (MEYER, 1974). Não era raro, portanto, que, durante a Época Moderna, uma cidade levasse duzentos anos para dobrar o número de habitantes.

Tabela 2 - População do Rio de Janeiro e das principais cidades portuguesas (estimativas aproximadas)

\begin{tabular}{cccccr}
\hline Cidade & 1750 & 1760 & 1800 & \% de Variação & Média anua \\
\hline & & & & & \\
Rio de Janeiro & & 32.000 & 43.000 & $+34,3$ & $+0,85$ \\
Lisboa & 185.000 & & 195.000 & $+5,4$ & $+0,10$ \\
Porto & 30.000 & & 43.000 & $+43,3$ & $+0,86$ \\
Braga & 15.000 & & 16.000 & $+6,6$ & $+0,13$ \\
Évora & 15.000 & & 12.000 & $-20,0$ & $-0,40$ \\
Coimbra & 14.000 & & 15.000 & $+7,1$ & $+0,14$
\end{tabular}

Fontes: Bairoch (1988, p. 57).

O Rio, como vimos, tal qual a cidade do Porto, fugia a esse padrão. A que devemos atribuir esse crescimento? Uma forma de o explicarmos é proporcionada pela análise comparativa. Entre 1750 e 1800, a Inglaterra liderou o processo mundial de urbanização. Da primeira à última data acima mencionada, Londres registrou um aumento populacional de $40 \%$, se aproximando, no início do século XIX, a um milhão de habitantes. Na mesma época, Liverpool e Manchester apresentaram índices de aumento da população extraordinários, vivenciando taxas de crescimento da 5 a $7 \%$ por ano. Nesse quadro europeu de urbanização intensa, em segundo lugar vinha a Rússia, onde Moscou e São Petersburgo registraram, nas referidas datas, taxas de incremento populacional anual da ordem de 2 a $3 \%$.

Ora, de acordo com as pesquisas existentes, as razões que levavam a esse intenso aumento populacional variaram de acordo com a sociedade analisada. No caso inglês, como seria de esperar, a rápida transformação das cidades tinha raízes econômicas, decorrendo da revolução industrial. Já na Rússia, o fenômeno urbano era expressão do processo de ocidentalização estimulado pelo governo monárquico (BAIROCH, 1988, p. 267).

Quando comparada a essas duas situações, a capital colonial parece se situar no meio termo. Embora, obviamente, estivesse longe de viver um processo semelhante ao inglês, cidade do Rio de Janeiro viveu no período acima indicado uma época de expansão da 
atividade comercial $^{6}$. Por outro lado, os efeitos da "ocidentalização" do espaço urbano carioca não devem ser descartados. Sede da Colônia desde de 1763, o Rio foi alvo de melhoramentos urbanísticos, principalmente no governo do Marquês do Lavradio (17691779), fato que deve ter feito do local um polo de atração da elite rural - que, por sua vez, trazia consigo numerosos escravos. A capital também passou a atrair numerosos homens livres, em busca de trabalho na abertura de ruas, aterros de pântanos e construção de obras no espaço urbano.

Esse crescimento, contudo, teve consequências nefastas, levando à multiplicação da população pobre na sociedade local. O estudo da "pobreza" implica em defini-la. Tal conceito, aliás, pode assumir diferentes sentidos, variando da "pobreza relativa" (desigualdade) à "pobreza absoluta" (miséria). Além disso, o pesquisador deve indicar se a pobreza é "individual" ou "familiar".

Na presente análise, opta-se pelo conceito de pobreza absoluta e individual, registrada em livros paroquiais de óbitos ${ }^{8}$ e em documentos hospitalares. As diferentes conjunturas da miséria estavam subordinadas a maior ou menor facilidade em se conseguir alimentos e moradia. Na verdade, o "milagre" da sobrevivência de muitos pobres ligava-se ao fato do Rio de Janeiro Setecentista ser um núcleo urbano com características ainda fortemente rurais. Nos fundos das palhoças era possível identificar uma incipiente economia de subsistência, que por vezes extrapolava o espaço dos domicílios. Os terrenos baldios, quintais das casas e chácaras permitiam a criação de pequenos animais e o estabelecimento de hortas e pomares. Não foram poucos os viajantes estrangeiros que observaram, um pouco perplexos, a relativa frequência com que rebanhos de carneiros, manadas de bois e varas de porcos pastavam pelas ruas, mesmo após a cidade ser elevada à condição de capital colonial (EDMUNDO, 1956, p. 14).

Para os que não dispunham de terrenos, mas possuíam armas e anzóis, a caça e a pesca também podia ser uma forma de suplementar a alimentação da família. Antigos cronistas registraram que, até bem avançado o século XVIII, continuou a existir vários tipos de peixes (traíras, bagres, cachimbaus, moçuns, saíras, piaus etc) nas lagoas localizadas no interior da

\footnotetext{
${ }^{6}$ A condição de cidade portuária nem sempre criava condições favoráveis ao crescimento demográfico. Às vezes, o inverso é que ocorria, devido ao recrutamento constante de homens adultos para o trabalho marítimo, cujas taxas de mortalidade eram elevadíssimas. Esse dado, aliás, é lembrado para explicar o fraco crescimento demográfico das cidades portuárias francesas: " la mortalité frappe lourdement les milieux maritimes... $60 \%$ des gens de mer meurent avant les quarante ans [...]". (BUTEL, 1997. p. 178).

${ }^{7}$ Outro elemento importante a ser sublinhado é a noção de ciclo de vida, que prevê a possibilidade de um indivíduo "nãopobre" vir a se tornar "pobre". Esse aspecto nem sempre tem sido levado em conta nas análises do período colonial, levando a distorções. Uma delas consiste em considerar a camada de artífices integralmente "não-pobre". Se levarmos em conta a noção de ciclo de vida, podemos em muito relativizar essa afirmação, pois um "sapateiro" aos 30 anos certamente não pode ser considerado "pobre", o mesmo nem sempre pode ser afirmado em relação a um "sapateiro" aos 80 anos, sem escravos ou apoio familiar. Aliás, o mesmo pode ser afirmado em relação aos pequenos proprietários rurais, definidos como "roceiros". (MELLO E SOUZA, 1982). Em relação aos conceitos de "pobreza", consultar o clássico: Woolf (1986. p. 1-6).

${ }^{8}$ Os dados de "óbitos de pobres" em registros paroquiais foram pioneiramente coletados por: (COSTA, 1979).
} 
cidade, onde também se registravam a presença de perigosos jacarés. Eis o que afirma, na primeira metade do século XIX, Balthazar da Silva Lisboa:

\begin{abstract}
A lagoa da Sentinella (atual rua Frei Caneca) era tão grande que se criavam jacarés; o Largo da Lampadosa (atual Campo de Santana) foi começado a entulhar-se no Vice-Reinado do Marquês do Lavradio [17691779], e dele se formalizou uma rua à esquerda daquela capela. Foi também um tremendo brejal, habitação de crocodilos (sic) a rua que depois se denominou do Propósito ou Bobadella (atual Gamboa) (LISBOA, 1840, v. 1, p. 52).
\end{abstract}

Quem pudesse se afastar rumo ao interior, em direção às matas de Campo Grande, consideradas, mesmo em meados do século XIX, ainda ... sertão, encontraria uma fauna ainda mais diversificada, constituída por antas, pacas, cotias, quatis, capivaras, tatus, jacutingas, macucos, preguiças, macacos e uma infinidade de outros animais (ALEMÃO, 1845). A caça e a pesca dependiam, porém, de recursos; dependiam de armas, de instrumentos apropriados e de deslocamentos em direção a regiões afastadas da cidade. Os homens em pleno vigor podiam ter essa chance, mas os velhos e os miseráveis estavam irremediavelmente excluídos dessa alternativa. Entre eles, a alimentação básica consistia quase sempre na dieta semelhante à consumida pelos escravos, ou seja, farinha de mandioca, carne ou peixe seco (EDMUNDO, 1956, v. 1, p. 122); tais comestíveis eram produzidos em abundância no recôncavo ou importados - como era o caso da carne-seca -, primeiramente do Nordeste e depois das regiões meridionais da Colônia.

As oscilações dos preços de bens de subsistência afetava gravemente o cotidiano dos cariocas mais pobres. As pesquisas realizadas, de certa maneira, permitem avaliar as conjunturas setecentistas mais desfavoráveis às camadas populares (JOHNSON, 1973, p. 231281). Grosso modo, os anos posteriores à elevação do Rio à condição de capital colonial foram de relativa bonança. Após a transferência da capital colonial, os preços da carne-seca e da farinha de mandioca sofreram uma queda acentuada e prolongada, com pequenas oscilações, por um período de dez anos. A partir de 1778, observa-se uma brusca variação, seguida do reinício de um ciclo de aumentos dos preços, que recuperam o patamar da década de 1760, registrando queda somente em 1805.

Em grande parte, tal evolução decorria das transformações registradas em Minas Gerais. Desde o início do século XVIII, áreas rurais do recôncavo da Guanabara se especializaram no fornecimento de alimentos às lavras mineiras. A partir de 1740 , a produção de ouro mineiro começou a dar sinais de crise, entrando em processo de declínio durante toda segunda metade do século XVIII (PINTO, 1979, p. 115). Sabemos hoje, porém, que essa crise, em vez de produzir uma estagnação econômica, estimulou o desenvolvimento de 
atividades alternativas, principalmente aquelas ligadas à agricultura comercial de subsistência e ao artesanato produtor de tecidos rústicos de algodão (LIBBY, 1988).

A produção de alimentos em grande quantidade permitiu às populações mineiras se tornarem independentes de boa parcela dos bens de subsistência que outrora eram importados de outras capitanias, favorecendo a queda nos preços dos alimentos na praça comercial carioca. Isso não impediu, porém, eventuais elevações nos preços dos bens de subsistência, em decorrência de fatores excepcionais. Na década de 1780 , por exemplo, essa elevação se vincula à súbita concentração de tropas na capital colonial - chegando a reunir onze mil homens destinados à proteção da região Sul (ALDEN, 1968, p. 263).

O aumento da população, associada à forte presença de militares em trânsito, também complicava a questão da moradia dos pobres. Uma maneira dos sem-domicílios coloniais sobreviverem era se tornando agregados, ou seja, moradores de favor; situação que implicava conseguir ser acolhido por algum parente, amigo ou protetor que fosse proprietário no meio urbano. A possibilidade de "agregação" também dependia do número de domicílios disponíveis a cada época. Em outras palavras, se a população aumentasse em um ritmo mais intenso do que o da edificação de casas, a procura por domicílios acolhedores deveria crescer, mas, com certeza, as chances de se conseguir "morar de favor" diminuíam.

Na tabela III analisamos essa situação. Como pode ser observado, no período que estamos investigando, a construção de novos domicílios ocorreu em um ritmo bem menor do que o do aumento da população carioca. Pode-se mesmo suspeitar de uma certa estagnação ou crise da atividade imobiliária local, tendo em vista que, entre 1780 e 1799, o número de imóveis diminui. Seria, dessa forma, tentador imaginar que, durante a segunda metade do século XVIII, os pobres do Rio de Janeiro dependeram cada vez mais da "moradia de favor" como uma forma de sobrevivência, mas, ao mesmo tempo, essa alternativa se tornou cada vez mais difícil de ser viabilizada. 
Tabela 3 - N. de imóveis e N. de habitantes no Rio de Janeiro, 1760-1808

\begin{tabular}{cccc}
\hline Ano & N. Abs. de Imóveis & $\begin{array}{c}\text { Índice de Aumento do N. } \\
\text { de Imóveis }\end{array}$ & $\begin{array}{c}\text { Índice de Aumento do N. } \\
\text { de Habitantes }\end{array}$ \\
\hline 1760 & 5.796 & 100 & 100 \\
1780 & 7.223 & 124,6 & 151,3 \\
1799 & 6.760 & 116,6 & 178,2 \\
1808 & 8.624 & 148,7 & 205.5 \\
\hline
\end{tabular}

Fonte: Cavalcanti (2004, p. 255, 278); Desobriga feita por Joaquim José Vieira e Luís Mendes dos Reis, oficiais da Câmara Eclesiástica (1787-1830). Livro n. 4, Arquivo da Cúria Arquidiocesana do Rio de Janeiro, s/cód..Somente as paróquias da Sé, Santa Rita, Candelária e Santa Rita.

Deve-se, porém, suspeitar das interpretações literais das fontes documentais, pois ser "agregado" não era necessariamente ser "pobre". Um português de passagem pelo Rio, às vezes mais rico do que o dono da casa em que estivesse hospedado, certamente não poderia ser considerado "pobre". Cabe lembrar, ainda, que na tabela III foram utilizados dados da documentação eclesiástica. Ora, o responsável pela listagem não contava com marcos simbólicos que o orientasse na delimitação do espaço carioca. Nesse sentido, é bastante sintomático que, na paróquia de São José, entre 1793 e 1794, tenham "desaparecido" 156 residências, enquanto entre 1797 e 1798 aí surgiram 73 novos domicílios. Portanto, é recomendável suspeitar que, em alguns anos, os dados da referida tabela também digam respeito a áreas fronteiriças da cidade, como Inhaúma e Engenho Velho.

Como se não bastassem esses problemas, é necessário sublinhar que, em nosso levantamento, estão incluídos imóveis comerciais, casas em "ruínas" e até mesmo "cercas" e "cocheiras". Na tabela IV excluímos esses últimos casos. Infelizmente, não é possível efetuar esse levantamento para o conjunto de períodos indicados anteriormente. Contudo, a análise de apenas um ano não deixa de ser reveladora. A nova tabela indica claramente uma hierarquia: morar em humildes casas "térreas simples" era o destino da maioria, enquanto ser proprietário de sobrado consistia em um privilégio de poucos, já desfrutar dos prazeres das chácaras era uma prerrogativa bastante restrita.

\footnotetext{
${ }^{9}$ Livro n. 4. Desobriga feita por Joaquim José Vieira e Luís Mendes dos Reis, oficiais da Câmara Eclesiástica (1787-1830). Arquivo da Cúria Arquidiocesana do Rio de Janeiro, s/cód.
} 
Tabela 4 - "Casas de Morada" no Rio de Janeiro, 1808

\begin{tabular}{ccc}
\hline Tipo & N.Abs & $\%$ \\
\hline Térrea & 4.702 & 66,8 \\
Sobrado* $^{*}$ & 2.217 & 31,5 \\
Chácara & 115 & 1,6 \\
\hline Total & 7.034 & 100,0
\end{tabular}

* incluído "sobradinhos" e "imóveis com sótão".

Fonte: Cavalcanti (2004, p. 266).

Em nossa análise, porém, o mais importante é sublinhar que esses variados tipos de moradias implicavam diferentes formas de acolhimento de agregados. A razão disso decorria do fato de ser possível, entre os proprietários de sobrados e de chácaras, destinar os cômodos inferiores aos moradores de favor, afastando assim os agregados pobres do convívio familiar da elite. Nos imóveis de apenas um andar, a situação era bem diferente, havendo uma obrigatória convivência e, por assim dizer, uma restrição do espaço destinado aos agregados.

Tabela 5 - Cor do "morador de favor" livre do Rio de Janeiro, 1799

\begin{tabular}{ccc}
\hline Cor & N. Abs. & $\%$ \\
\hline Branca & 5.608 & 76,6 \\
Parda & 1.007 & 13,7 \\
Preta & 700 & 9,5 \\
\hline Total & 7.315 & 100,0 \\
\hline
\end{tabular}

Fonte: Resumo total da população que existia no ano de 1799 , compreendidas as quatro freguesias desta cidade do Rio de Janeiro. Revista do Instituto Histórico e Geográfico Brasileiro, 1858, v. XXI, p. 216-217.

Ora, a condição de hóspede "de favor", como o próprio termo sugere, não deveria implicar em pagamento algum. Por isso mesmo, o chefe do domicílio podia selecionar aqueles que seriam acolhidos nessa condição. Conforme mencionamos, um português, recém-chegado à cidade, com certeza, contaria com a generosidade dos proprietários locais. Tal situação, de certa maneira, ficou documentada no levantamento populacional de 1799. 
Segundo os dados do documento, a população "branca" predominava entre os homens e mulheres que conseguiam ser aceitos como moradores de favor.

A exclusão de muitos afrodescendentes livres - aqueles que deviam constituir a camada mais pobre da sociedade colonial - ficou registrada em outros documentos. Em algumas ocasiões, os párocos anotavam o local de residência dos agregados nos livros de óbitos das igrejas. Como tal anotação não era sistemática, é arriscado avaliá-las estatisticamente. No entanto, o levantamento de testemunhos qualitativos confirma as informações apresentadas. Nas atas percebe-se que os agregados "de cor" eram raros e tendiam a ser originários do mesmo meio social do dono ou dona da casa ou mesmo ser parentes desses últimos. Assim, em 1792, ao se registrar, na igreja do Santíssimo Sacramento, a ata de óbito de Luíza da Conceição, o pároco fez a seguinte observação: parda forra viúva, agregada em casa de Benedito da Costa, crioulo forro, casado com Luíza Teixeira, também crioula forra ${ }_{. . .}^{10} \mathrm{O}$ mesmo ocorreu em outra ata, quase da mesma data, que indicava o falecimento de uma certa Maria da Assumpção, observando que a mesma era agregada atrás de S. Francisco de Paula (sic.), na rua do Cano ... em casa de Ana Maria da Conceição, sua sobrinha. ${ }^{11}$

Por outro lado, as atas paroquiais também são ricas em exemplos de indivíduos pobres que, pelo menos aparentemente, não eram moradores de favor:

... faleceu da vida presente Francisco Borges Quintal, casado com Rosa Maria das Neves, ambos pardos forros, com todos os sacramentos, que vivia de cacheiro de uma banca de peixe, homem pobre, sem bem algum, morador na Rua Velha...

... faleceu só com o sacramento da Penitência, Clara da Cruz, parda forra, viúva, e não soube dizer de quem, muito pobre segundo me constou, vivia de esmolas, moradora na Rua do Piolho... ${ }^{13}$

.... faleceu da vida presente Antonia Francisca Xavier viúva de quem não me souberam dizer, mulher mui pobre, que vivia de esmolas, e moradora na Rua Nova do Lavradio...

A menção à "rua" era utilizada para aqueles que dispunham de habitação própria, denominados, na época, como chefes de domicílio. Os exemplos acima mencionados

\footnotetext{
${ }^{10}$ Registro de óbito de 14 de setembro de 1792. Livro de Óbito da Igreja do Santíssimo Sacramento, 1790-1797, Arquivo da Cúria Arquidiocesana do Rio de Janeiro, s/cód. Grifo nosso.

11 Registro de óbito 16 de setembro de 1792. Livro de Óbito da Igreja do Santíssimo Sacramento, 1790-1797, Arquivo da Cúria Arquidiocesana do Rio de Janeiro, s/cód. Grifo nosso..

${ }^{12}$ Registro de óbito de 17 de setembro de 1792. Livro de Óbito da Igreja do Santíssimo Sacramento, 1790-1797, Arquivo da Cúria Arquidiocesana do Rio de Janeiro, s/cód. Grifo nosso.

${ }^{13}$ Registro de óbito de 20 de setembro de 1792. Livro de Óbito da Igreja do Santíssimo Sacramento, 1790-1797, Arquivo da Cúria Arquidiocesana do Rio de Janeiro, s/cód. Grifo nosso..

${ }^{14}$ Registro de óbito de 21 de setembro de 1792. Livro de Óbito da Igreja do Santíssimo Sacramento, 1790-1797, Arquivo da Cúria Arquidiocesana do Rio de Janeiro, s/cód. Grifo nosso..
} 
poderiam ser interpretados como ocorrências excepcionais se não fossem confirmados por outros testemunhos de época. Assim, ao compararmos a Tabela V com a VI, veremos que o número de pardos livres "chefes de domicílio" era mais elevado do que o de "moradores de favor" dessa mesma cor. No caso dos "pretos livres", essa desproporção era ainda mais acentuada: existiam duas vezes e meio mais "pretos chefes de domicílios" do que "pretos moradores de favor".

Tabela 6 - Cor do "chefe de domicílio" no Rio de Janeiro, 1799

\begin{tabular}{ccc}
\hline Cor & N. Abs. & $\%$ \\
\hline Branco & 7.104 & 68,4 \\
Pardo & 1.401 & 13,5 \\
Preto & 1.867 & 18,0 \\
\hline Total & 10.372 & 100,0 \\
\hline
\end{tabular}

Fonte: Resumo total da população que existia no ano de 1799, compreendidas as quatro freguesias desta cidade do Rio de Janeiro. Revista do Instituto Histórico e Geográfico Brasileiro, 1858, v. XXI, p. 216-217.

Embora o aluguel de casa fosse uma prática corrente na época, é pouco provável que os afrodescendentes livres conseguissem arcar com esse pagamento. Também não foram ainda identificados domicílios coletivos, à semelhança dos cortiços de fins do século XIX. Para muitos a solução de moradia consistia na construção de pequenos casebres, em que pudessem residir por conta própria. Por serem construções precárias e de limitado espaço físico, tais casebres aceitavam poucos moradores de favor. O que, por sua vez, levava à construção de novas habitações modestas, fenômeno, aliás, registrado nas entrelinhas de testamentos setecentistas, como o de um forro mina possuidor de duas moradas de casa de meia água de pau a pique ... no Campo de São Domingos. ${ }^{15}$

Com barro batido, mariscos, cipós, madeira e folhas, os pobres construíam suas casas que, em muito pouco, se diferenciavam das senzalas destinadas aos escravos. Contudo, eles enfrentavam um grande desafio: os terrenos não ocupados eram raros ou estavam localizados em locais de difícil edificação. A razão disso se prendia ao fato de o espaço urbano, da segunda metade do século XVIII, estar quase todo aforado (BICALHO, 2003, p. 208) pela câmara a particulares.

\footnotetext{
15 Testamento de Luis Fagundes, preto forro de nação mina, 30/10/1751. Livro de Óbito da Sé, 1746-1768. Arquivo da Cúria Arquidiocesana do Rio de Janeiro, s/cód.
} 
Uma forma frequente de as irmandades e confrarias investirem seus recursos era através da compra de imóveis. Com o passar do tempo, as instituições eclesiásticas cariocas tornaram-se importantes agentes imobiliários do espaço urbano, como ocorreu entre os jesuítas que, em 1759, eram os principais proprietários urbanos do Rio de Janeiro (FRIDMAN, 1999, p. 49). Outros indícios revelam, por sua vez, que esse não era um caso isolado. Na mesma época que os membros da Companhia de Jesus estavam sendo expulsos da Colônia, o aluguel de casas rendia aos beneditinos cariocas três vezes mais do que seis fazendas de gado e de açúcar pertencentes à Ordem (FRIDMAN, 1999, p. 235). Os carmelitas não ficavam atrás: em fins do século XVIII, declararam possuir uma centena de imóveis na cidade e imediações do Rio de Janeiro (FRIDMAN, 1999, p. 281).

A transformação das esmolas e legados pios em casas e terrenos alimentava a tendência do controle do espaço urbano por parte da Igreja. Paralelamente a isso, os poderosos cariocas beneficiavam-se dos laços mantidos com a governança da Câmara para conseguir privilégios no acesso às terras da cidade. Esse procedimento consistia em "aforar" terrenos a preços bastante reduzidos e por prazos indeterminados; irregularidade alvo de um processo em 1770 (BICALHO, 2003, p. 247), mas que, conforme pode ser observado nas queixas das décadas posteriores, continuou a ser prática recorrente. Em 1817, Antonio Alves de Araújo afirmou em relação à capital carioca: ...meia dúzia de pessoas apoderam-se, e repartem entre si os terrenos, para os aforar e arrendar depois por preços enormes... (ARAÚJO, 1817)

Entre esses poderosos especuladores, há de se assinalar a presença dos traficantes de escravos. Como é sabido, o empreendimento de compra e venda de cativos africanos consistia em negócio que podia render lucros elevadíssimos (FLORENTINO, 2001), mas também era bastante arriscado. Ataques de piratas, doenças e incertezas da rota atlânticas podiam causar gravíssimos prejuízos, sendo esse tipo de comércio, por isso mesmo, denominado por alguns autores como capitalismo de loteria (PÉTRÉ-GRENOUILLEAU, 1996, p. 66). No intuito de não ficar inteiramente à mercê de tais riscos, os traficantes voltavam-se para investimentos seguros, ou que produzissem rendas estáveis, como eram os casos de compras de terrenos e imóveis, destinados ao aluguel ou como simples reserva de valor. ${ }^{16}$

Aos pobres restava ocupar áreas consideradas impróprias à edificação urbana. Os pardieiros, palhoças, casinholas e casa de pau a pique floresciam nesses insalubres territórios. Por outro lado, certos locais, apesar de estarem localizados em áreas centrais do meio urbano, permaneceram durante várias décadas desocupados pela elite, sendo local de moradia de pobres e negros. Os becos, particularmente, eram vistos como antros de várias

\footnotetext{
16 Em relação ao período compreendido entre 1799 e 1808, é possível afirmar que, entre os traficantes cariocas, a especulação urbana consistiu na principal atividade econômica "interna" à Colônia, superando o investimento na compra de fazendas e de engenhos. (FLORENTINO, 1995. p. 207, 281).
} 
insolências (BICALHO, 2003, p. 243) e às vezes espaço de domínio africano, como sugere a designação de Beco do Sarará.

Uma vez esgotada a possibilidade de ocupar terrenos urbanos, restava aos pobres os territórios nos arrabaldes da cidade. Tendo em vista a história contemporânea do Rio de Janeiro, a primeira opção a ser imaginada seria a de ocupação dos morros cariocas. De fato isso ocorreu, mas de forma muito restrita, pois áreas próximas à cidade, como o Morro de Santa Tereza, eram dominadas por quilombolas, que tratavam de expulsar os recémchegados. ${ }^{18}$ As áreas localizadas rumo ao interior eram, por sua vez, quase todas ocupadas por chácaras ou fazendas açucareiras. A alternativa à cidade consistia, portanto, em se deslocar para as praias, consideradas "terra de ninguém", sendo inclusive possível identificar, através dos registros paroquiais, libertos e libertas que, desde a década de 1760, moravam nas imediações do Catete ${ }^{19}$ e, nos anos 1780 , em Laranjeiras, ${ }^{20}$ Praia Vermelha ${ }^{21}$ e Leme. $^{22}$

No entanto, para que tais deslocamentos fossem bem sucedidos, era necessário que os pobres contassem com recursos mínimos para aquisição de pequenas embarcações e ferramentas. Aos idosos, crianças e miseráveis, com certeza, estava vetada essa possibilidade, ao mesmo tempo em que a precariedade de muitos casebres e a seletividade da moradia de favor os ameaçavam com o risco de ter de dormir ao relento, nos becos e praias da capital carioca.

Sem alimento e sem lugar para morar, o destino dos pobres era o de morrer precocemente sendo enterrados como indigentes pela Santa Casa da Misericórdia. Desde fins do século XVII, o óbito desse segmento constituiu séria preocupação das autoridades cariocas.

17 Ata de batismo de 26 de maio de 1786. Livro de batismo da paróquia de São José (1785-1790). Arquivo da Cúria Arquidiocesana do Rio de Janeiro, s/cód.

18 FRIDMAN (1999. p. 35) A autora menciona, para o ano de 1699, a existência de um quilombo em Santa Tereza,e AMANTINO (1998, p. 118) identifica, na mesma área, uma comunidade quilombola em 1823. O que sugere a permanência secular desses grupos nos morros próximos ao Rio de Janeiro colonial.

${ }^{19}$ Ata de batismo de 10 de dezembro de 1767. Livro de batismo da paróquia de São José (1767-1785). Arquivo da Cúria Arquidiocesana do Rio de Janeiro, s/cód.

20 Ata de batismo de 19 de janeiro de 1782. Livro de batismo da paróquia de São José (1767-1785). Arquivo da Cúria Arquidiocesana do Rio de Janeiro, s/cód.

${ }^{21}$ Ata de batismo de 09 de setembro de 1781. Livro de batismo da paróquia de São José (1767-1785). Arquivo da Cúria Arquidiocesana do Rio de Janeiro, s/cód.

22 Ata de batismo de 19 de abril de 1788. Livro de batismo da paróquia de São José (1785-1790). Arquivo da Cúria Arquidiocesana do Rio de Janeiro, s/cód. 
Tabela 7 - Óbitos de pobres na Santa Casa da Misericórdia do Rio de Janeiro, 1763-1808

\begin{tabular}{rrrrrr}
\hline Ano & Ob. de pobres & Ano & Ob.de pobres & Ano & Ob. de pobres \\
& & & & & \\
\hline 1763 & 84 & 1779 & 90 & 1795 & 201 \\
1764 & 86 & 1780 & 119 & 1796 & 149 \\
1765 & 74 & 1781 & 130 & 1797 & 170 \\
1766 & 69 & 1782 & 170 & 1798 & 154 \\
1767 & 67 & 1783 & 142 & 1799 & 175 \\
1768 & 91 & 1784 & 157 & 1800 & 194 \\
1769 & 107 & 1785 & 152 & 1801 & 229 \\
1770 & 84 & 1786 & 192 & 1802 & 254 \\
1771 & 119 & 1787 & 158 & 1803 & 262 \\
1772 & 116 & 1788 & 197 & 1804 & 248 \\
1773 & 104 & 1789 & 242 & 1805 & 402 \\
1774 & 124 & 1790 & 183 & 1806 & 345 \\
1775 & 144 & 1791 & 243 & 1807 & 335 \\
1776 & 126 & 1792 & 228 & 1808 & 381 \\
1777 & 93 & 1793 & 202 & & \\
1778 & 100 & 1794 & 166 & & \\
\hline
\end{tabular}

Fonte: Almeida (1899).

Aliás, se aceitarmos os óbitos de pobres como uma espécie de "termômetro" da pobreza carioca, perceberemos que as décadas de 1760 e 1770 foram favoráveis a esse segmento. Em vários anos se registram, inclusive, um declínio destas ocorrências: 1765, 1767, 1770, 1772, 1773, 1776, 1777 e 1779. Esses dados, com certeza, devem ser interpretados com cautela, pois diversas igrejas, via donativos de irmandades ou com recursos paroquiais, também enterravam gratuitamente. Os dados da Santa Casa são apenas uma amostragem, em um universo social bem mais amplo. A partir de 1780, também se constatam momentos de declínio do número de óbitos de pobres, mas agora esse fenômeno é seguido de intenso aumento: entre 1780 e 1789 os números dobram. No início do século XIX, registra-se sua explosão: em 1805 o número é quase $500 \%$ superior ao de 1765 !

A interpretação mais óbvia desses dados seria a de atribuí-los ao crescimento populacional, ou seja, multiplicou o número de óbitos de pobres devido ao aumento do número de habitantes. A comparação entre os dados das tabelas I e VII revela, porém, que a 
população crescia em ritmo bem mais lento do que o número de óbitos de pobres. Esse crescimento se associava a outros fenômenos. $\mathrm{O}$ aumento dos preços dos alimentos e a falta de moradia fragilizavam a vida dos mais carentes, os tornando mais vulneráveis às doenças que assolavam a cidade. As primeiras cartas do Marquês do Lavradio, quando então ele assumiu o governo da Colônia, guardam sinceros queixumes em relação às péssimas condições de salubridade da capital. Viver no Rio, segundo o vice-rei, era viver mal. Em 1770 ele escrevia ao colega, Marquês de Penalva, nos seguintes termos:

\begin{abstract}
Cheguei finalmente meu Exmo. ao Rio de Janeiro o qual logo me recebeu como se ele soubesse o pouco que sempre desejei vir fazer-lhe esta visita, é certo que a má situação desta terra, não pode deixar de o [a] fazer sumamente doentia; por ter sido edificada em um terreno muito baixo onde se juntam as imensas águas que correm dos inacessíveis montes de que é cercada, e como a estas se lhe[s] não tem procurado dar saída, ficam ali estagnadas, e logo com os grandes sóis todas elas se corrompem, e desta forma fica sendo bem evidente que uma terra semelhante sem se lhe remediar este defeito não poderá nunca vir a ser sadia, e daqui nasce[m] os grandíssimos achaques que todos padecem... (MARQUÊS DO LAVRADIO, 1975, v. 1, p. 94).
\end{abstract}

Contudo, o vice-rei reconhecia a ausência de epidemias fatais, sublinhando, em carta ao Conde de Prado, a existência de doenças que não matavam de imediato, mas provocavam problemas de saúde que voltavam de tempos em tempos: .. é esta terra bastantemente doentia não de moléstias agudas mas de achaques que é rara a pessoa que não padeça. Os pântanos e brejos que cercavam a cidade constituíam em lugar propício para multiplicação de insetos responsáveis delas disseminação das moléstias periódicas. Quando elas ocorriam em épocas de difícil acesso aos alimentos, os "achaques" podiam se tornar fatais, aumentando assim o número de pobres enterrados gratuitamente no cemitério da Santa Casa.

Dessa forma, as primeiras décadas do século XIX foram de grande sofrimento para os pobres cariocas, que faleceram em número bem mais elevado do que os índices de crescimento da população. Em 1808, a chegada da família real intensificará o quadro de penúria. A abertura dos portos destruirá parte importante do artesanato urbano, florescentes desde fins do século XVIII. ${ }^{23}$ Os preços dos alimentos, devido ao aumento da demanda, registram um novo período de ascensão. Aliado a isso, a transferência de parte

\footnotetext{
${ }^{23}$ Uma história da destruição do artesanato carioca colonial ainda está para ser escrita. Em relação a seu florescimento no século XVIII. (LIMA, 2008, p. 237). No que diz respeito a seu declínio, os dados são expressivos. Eis um exemplo: em 1799 existiam 135 sapateiros (que não só consertavam, mas também produziam sapatos) no Rio de Janeiro; em 1822 esse número havia diminuído para apenas 9. A diminuição de artífices também é registrada em outras áreas: violeiros, espingardeiros, chapeleiros etc. Há, ainda, ocupações que desaparecem entre a primeira e a última data, como foi o caso dos seleiros. (LOBO, 1987, v. I, p. 70-71 e 133-135).
} 
significativa da corte portuguesa intensificará a disputa pelo monopólio do solo urbano. ${ }^{24} \hat{E}$ nesse contexto que se deve entender as tensões sociais às vésperas da Independência, mas isso é uma outra história ....

\section{Referências}

ALDEN, Dauril. Royal government in colonial Brazil: with special reference to the administration of the Marquis of Lavradio, Viceroy, 1769-1779. Los Angeles: University of California Press, 1968.

ALEMÃO, Francisco Freire. Caça que existiu ou que ainda existe nas matas virgens de Campo Grande. Biblioteca Nacional, Seção de Manuscritos, cód. I, 28,9,48. 1845.

ALMEIDA, P. A. A Santa Casa da Misericórdia do Rio de Janeiro. Jornal do Commércio, 8 de julho de 1899.

ARAUJO, Antonio Alves. Reflexões sobre a edificação de novas casas na cidade do Rio de Janeiro. Seção de Manuscritos da Biblioteca Nacional do Rio de Janeiro, cód. 22,1,10. 1817.

BAIROCH, Paul et al. La population des villes européennes: banque de donnés et analyse sommaire des résultats: 800-1850. Géneve: Droz, 1988.

BERNARDES, Lysia. Função defensiva do Rio de Janeiro e seu sítio original. Boletim Carioca de Geografia, Rio de Janeiro, v. 13, p. 92, 1960.

BICALHO, Maria Fernanda. A cidade e o império: o Rio de Janeiro no século XVIII. Rio de Janeiro: Civilização Brasileira, 2003.

BUTEL, Paul. Européens et espaces maritimes (vers 1690-vers 1790). Bordeaux: Presses Universitaires de Bordeaux, 1997.

CAVALCANTI, Nireu Oliveira. O Rio de Janeiro setecentista: a vida e a construção da cidade da invasão francesa até a chegada da Corte. Rio de Janeiro: Zahar, 2004.

COSTA, Iraci Del Nero da; GUTIERREZ, Horácio. Paraná: mapas de habitantes, 1798-1830. São Paulo: IPE/USP, 1985.

COSTA, Iraci Del Nero da. Vila Rica: população (1719-1826). São Paulo: IPE/USP, 1979.

\footnotetext{
${ }^{24}$ Ainda está indefinido o número de pessoas que compunha a "corte”, mas, independente desse número, a mudança teve grande impacto na vida local. (MALERBA, 2008. p. 160-176).
} 
EDMUNDO, Luiz. O Rio de Janeiro no tempo dos vice-reis. Rio de Janeiro: Conquista, 1956. v. 1.

FLORENTINO, Manolo Garcia. Em Costas Negras: uma história do tráfico atlântico de escravos entre a África e o Rio de Janeiro (séculos XVIII e XIX). Rio de Janeiro: Arquivo Nacional, 1995.

FLORENTINO, Manolo Garcia; FRAGOSO, João. O arcaísmo como projeto: mercado atlântico, sociedade agrária e elite mercantil em uma economia colonial tardia: Rio de Janeiro (17901840). Rio de Janeiro: Civilização Brasileira, 2001.

FRANÇA, Jean Marcel Carvalho. Visões do Rio de Janeiro: antologia de textos, 1531-1800. Rio de Janeiro: José Olympio/EDUERJ, 1999.

FRIDMAN, Fania. Donos do Rio em nome do rei: uma história fundiária da cidade do Rio de Janeiro. Rio de Janeiro: Zahar, 1999.

JOHNSON JUNIOR, Harold. A preliminary inquiry into money, prices, and wages in Rio de Janeiro, 1763-1823. Colonial roots of modern Brazil, Berkeley, p. 231-281, 1973.

JOHNSON, M. H. Money and prices in Rio de Janeiro. L'histoire quantitative du Brésil. Paris: CNRS, 1973.

LIBBY, Douglas Cole. Transformação e trabalho em uma economia escravista: Minas Gerais no século XIX. São Paulo: Brasiliense, 1988.

LIMA, Carlos. Artífices do Rio de Janeiro (1790-1808). Rio de Janeiro: Apicuri, 2008.

LISBOA, Balthazar da Silva. Annaes do Rio de Janeiro. Rio de Janeiro: Typographia Imperial, 1840. v. 1.

LOBO, E. M. L. História do Rio de Janeiro (do capital comercial ao capital industrial e financeiro). Rio de Janeiro: IBEMEC, 1987. v. 1.

MALERBA, Jurandir. Sobre o tamanho da comitiva. In: SCOTT, Ana Silvia Volpi; FLECK, Eliane Cristina Deckmann. A corte no Brasil: população e sociedade no Brasil e em Portugal no início do século XIX. São Leopoldo: Oikos, 2008. p. 160-176.

MARCILIO, Maria Luíza. A cidade de São Paulo: povoamento e população, 1750-1850. São Paulo: Pioneira/EDUSP, 1973.

MARQUÊS DO LAVRADIO. Cartas do Rio de Janeiro (1769-1776). Rio de Janeiro: Arquivo Nacional, 1975, v. I, p. 94. 
MATTOSO, Kátia Queirós. Bahia, século XIX: uma província no Império. Rio de Janeiro: Nova Fronteira, 1992.

MELLO E SOUZA, Laura de. Desclassificados do ouro: a pobreza mineira no século XVIII. Rio de Janeiro, Graal, 1982.

MEYER, Jean. Quelques vues sur l'histoire des villes à l'époque moderne. Annales Économies, Sociétés, Civilisations, Paris, v. 29, n. 6, p. 1551-1568, 1974.

MORSE, Richard (Ed.). The urban development of Latin America, 1750-1920. Stanford: Center for Latin American Studies, 1971.

NASCIMENTO, Ana Amélia Vieira. Dez freguesias da cidade do Salvador. Salvador: Fundação Cultural do Estado da Bahia, 1986.

NASH, Gary. The social evolution of preindustrial american cities, 1700-1820. Jounal of Urban History, v. 13, n. 2, p. 115, 1987.

PÉTRÉ-GRENOUILLEAU, Olivier. L'Argent de la traite: milieu négrier, capitalisme et développement - um modèle. Paris: Aubier, 1996.

PINTO, Virgílio Noya. O ouro brasileiro e o comércio anglo-português. São Paulo: Ed. Nacional, 1979.

RAMOS, Donald. Vila Rica: profile of a colonial brazilian urban center. The Americas, v. 35, n. 4, p. 496, 1979.

SANTOS, Francisco Noronha. As freguesias do Rio de Janeiro. Rio de Janeiro: Cruzeiro, 1965.

SOUZA, Jorge Prata de. Escravidão: ofícios e liberdade. Rio de Janeiro: APERJ, 1998.

VENANCIO, Renato Pinto. Vila Rica: prosperité et déclin urbain dans le Minas Gerais (XVIIIXX siècles). In: VIDAL, Laurent (Org.). La ville au Brésil (XVIIIe-XXe siècles) naissances et renaissances. Paris: Rivages des Xantons, 2008. p. 179-204.

WOOLF, Stuart. The poor in western Europe in the Eighteenth and Nineteenth centuries. Londres: Methuen, 1986. 